Note

\section{Formation of 2,6- Dihydroxyphenylacetic Acid from Phenylacetic Acid by Trichosporon cutaneum}

\author{
Teruo Ueno, Isao Morishima, \\ Satoshi Sugiura, Takaaki Araki \\ and Fumiki YoshizaKo* \\ Department of Agricultural Chemistry, \\ Faculty of Agriculture, University of Tottori, \\ Tottori 680, Japan \\ *Department of Applied Biology, \\ Radiation Center of Osaka Prefecture, \\ Shinkecho, Sakai, Osaka 593, Japan
}

Received September 18, 1986

In investigations on the metabolism of phenylacetic acid (PA) by microorganisms, the formation of homogentisic acid (2,5-DHPA $)^{1 \sim 11)}$ or homoprotocathechuic acid $(3,4-$ DHPA), ${ }^{12 \sim 14)}$ or both, ${ }^{11,15)}$ has been demonstrated. We previously reported that the ability to convert PA into 2,6dihydroxyphenylacetic acid (2,6-DHPA) is widely present in fungi, especially in Aspergillus and Penicillium species, ${ }^{11}$ and that 2,6-DHPA was formed from PA via ohydroxyphenylacetic acid (2-HPA) by Aspergillus fumigatus. ${ }^{8)}$ This paper presents the results of a screening test for yeasts which are able to produce 2,6-DHPA from PA, and reports that 3 strains of Trichosporon cutaneum selected as 2,6-DHPA producers, unlike the strain of $T$. cutaneum reported by Dagley's group, ${ }^{10,17)}$ converted PA into 2,5- and 2,6-DHPA via 2-HPA, and into 3,4-DHPA via $m$-hydroxyphenylacetic acid (3-HPA), respectively.

The following 90 strains of yeasts ( 18 genera, 76 species) were screened for the production of 2,6-DHPA from PA: Saccharomyces, 22 strains; Candida, 18; Rhodotorula, 10;
Hansenula, 8; Pichia, 6; Torulopsis, 6; Trichosporon, 4; Kloeckera, 2; Sporobolomyces, 3; Cryptococcus, 2; Endomyces, 2; and one each of strains of Endomycopsis capsularis, Schizosaccharomyces pombe, Debaryomyces hansenii, Saccharomycodes ludwigii, Hanseniaspora valbyensis, Wickerhamia fluorescens and Torula rubura var. alpha. These strains were grown with shaking (rotary, $200 \mathrm{rpm})$ at $30^{\circ} \mathrm{C}$ for $3 \sim 5$ days in $100 \mathrm{ml}$ of medium (pH 6.0) containing malt extract $(2.0 \%)$, glucose $(1.0 \%)$, peptone $(0.1 \%)$ and PA $(0.05 \%)$. The cells were harvested in the late logarithmic phase of growth by centrifugation and then washed three times with sterile saline. The washed cells were suspended in $20 \mathrm{ml}$ of $0.2 \mathrm{M} \mathrm{Na} \mathrm{HPO}_{4}-0.1 \mathrm{M}$

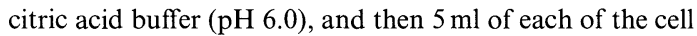
suspensions was added to $50 \mathrm{ml}$ of the same $\mathrm{Na}_{2} \mathrm{HPO}_{4}$ citric acid buffer in a $300 \mathrm{ml}$ Erlenmeyer flask containing one of the substrates $(0.05 \%)$ : PA for the screening test; and PA, 2-HPA, 3-HPA and $p$-hydroxyphenylacetic acid (4-HPA) for the metabolic study. The cultures were incubated at $30^{\circ} \mathrm{C}$ on a rotary shaker $(200 \mathrm{rpm})$ for $3 \sim 170 \mathrm{hr}$.

After incubation for a given period, the culture filtrate was acidified to $\mathrm{pH} 2.0$ with $\mathrm{H}_{2} \mathrm{SO}_{4}$ and then extracted with ethylacetate. The ethylacetate extract was concentrated and subjected to thin-layer chromatography (TLC). The concentrated extract was also silylated with $\mathrm{N}, \mathrm{O}$-bis(trimethylsilyl)-acetamide in acetonitrile and then submitted to gas-chromatography (GC). GC was performed with a Shimadzu GC-4B chromatograph on a glass column $(1.5 \mathrm{~m} \times 0.3 \mathrm{~cm}$ i.d. $)$ packed with SE-30. The gas flow rate for $\mathrm{N}_{2}$ was $30 \mathrm{ml} / \mathrm{min}$. The temperature was increased from the initial $100^{\circ} \mathrm{C}$ to a final $250^{\circ} \mathrm{C}$ at a rate of $10^{\circ} \mathrm{C} / \mathrm{min}$. The silylated derivatives of $\mathrm{PA}$ and its metabolites were identified by comparing their retention times with those of authentic samples and by cochromatography. Since the derivatives of 2,5- and 3,4-DHPA showed the same retention time values, the formation of these compounds was confirmed by TLC and GC-mass spectrometry (GC-MS). Detection and identification of the metabolites by TLC, UV and GC-MS were carried out as described previously. ${ }^{4,8,19)}$ PA was determined by Yoshii's colorimetric method. ${ }^{18)}$

Among the 90 strains investigated in the screening test, 3

Table I. Formation of Various Metaboltes from Phenilacetic Acid and Its Hydroxy Derivatives By $T$. cutaneum YTr-1, YTr-2 and KUY-6A

\begin{tabular}{ccccccc}
\hline & \multicolumn{7}{c}{ Metabolites } \\
\cline { 2 - 7 } Substrate & 2-HPA & 3-HPA & 4-HPA & 2,5 -DHPA & 2,6-DHPA & 3,4-DHPA \\
\hline PA & + & + & \pm & + & + & - \\
2-HPA & nd & - & - & + & + & - \\
3-HPA & - & nd & - & + & - & + \\
4-HPA & - & - & nd & - & - & + \\
\hline
\end{tabular}

nd, not determined. 


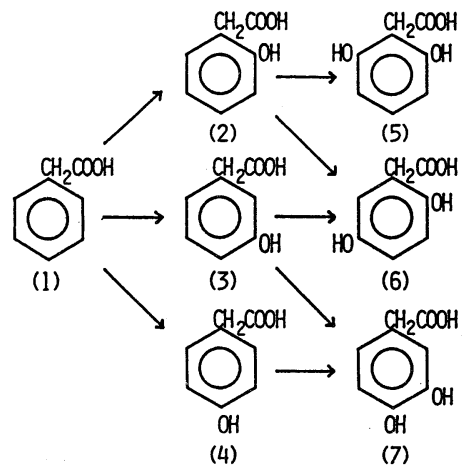

Fig. 1. Proposed Metabolic Sequence for PA Catabolism in T. cutaneum YTr-1, YTr-2 and KUY-6A.

(1) PA; (2) 2-HPA; (3) 3-HPA; (4) 4-HPA; (5) 2, 6-DHPA; (6) 2, 5-DHPA; (7) 3, 4-DHPA.

strains of Trichosporon cutaneum (T. cutaneum YTr-1, YTr-2 and KUY-6A) alone were able to produce 2,6DHPA from PA. These 3 strains of $T$. cutaneum consumed about $50 \%$ of the PA on incubation for $48 \mathrm{hr}$ and $90 \%$ in $168 \mathrm{hr}$. In addition to 2,6-DHPA, these strains produced 2HPA, 3-HPA, 4-HPA (trace amount) and 2,5-DHPA from PA, however, 3,4-DHPA was not detected in the culture filtrates. When monohydroxyphenylacetic acid was used as a substrate, the 3 strains converted 2-HPA into 2,5- and 2,6-DHPA, 3-HPA into 2,5- and 3,4-DHPA, and 4-HPA into 3,4-DHPA, respectively (Table I).

The conversion of 2-HPA to 2,5-DHPA ${ }^{1,5 \sim 9)}$ and 2,6DHPA, ${ }^{8,16)}$ that of 3 -HPA to $2,5-\mathrm{DHPA}^{8 \sim 10,15,21)}$ and $3,4-\mathrm{DHPA},{ }^{20}$ ) and also that of 4-HPA to 3,4DHPA $^{10,12 ~ 15,17)}$ have been verified in microorganisms, however, no report on the conversions described above, except for the conversion of 3-HPA to 2,5-DHPA ${ }^{10)}$ and that of 4-HPA to $3,4-$ DHPA,${ }^{10,17)}$ have so far appeared for yeasts. This is the first report of the formation of 2,5- and 2,6-DHPA from PA via 2-HPA and that of 3,4-DHPA from 3-HPA by a yeast, T. cutaneum. 3,4-DHPA was not detected in the culture filtrate on incubation with PA, however, the formation of 3-HPA and 4-HPA from PA and that of 3,4-DHPA from 3-HPA and 4-HPA were revealed (Table I), and hence, the 3 strains of $T$. cutaneum may have a metabolic pathway from PA through 3-HPA and 4-HPA to 3,4-DHPA. From the results obtained in this work, a metabolic sequence for the PA catabolism in T. cutaneum YTr-1,YTr-2 and KUY-6A is proposed (Fig. $1)$.
Acknowledgments. We appreciate the help by Dr. M. Chubachi (Radiation Center of Osaka Prefecture) in the mass spectrometric analysis and by Dr. Y. Hasegawa (Kansai University, Osaka) who supplied the T. cutaneum KUY-6A.

\section{REFERENCES}

1) M. Isono, Nippon Nôgeikagaku Kaishi, 28, 475 (1954).

2) A. J. Kluyver and J. C. M. van Zijp, Antonie van Leeuwenhoek; J. Microbiol. Serol., 17, 315 (1951).

3) S. M. Bocks, Phytochemistry, 6, 785 (1967).

4) T. Ueno, F. Yoshizako and A. Nishimura, Can. J. Microbiol., 19, 393 (1973).

5) K. Yuasa, K. Ishizuka, S. Kaburaki and T. Sakasai, Agric. Biol. Chem., 39, 2199 (1975).

6) G. Kishore, M. Sugumaran and C. S. Vaidyanathan, J. Bacteriol., 128, 182 (1976).

7) M. Sugumaran and C. S. Vaidyanathan, J. Indian Inst. Sci., 60, 125 (1978).

8) F. Yoshizako, A. Nishimura and T. Ueno, Nippon Nôgeikagaku Kaishi, 56, 1135 (1982).

9) N. Kunita, Med. J. Osaka Univ., 6, 703 (1955).

10) J. J. Anderson and S. Dagley, J. Bacteriol., 141, 534 (1980).

11) F. Yoshizako, T. Ueno, I. Morishima, T. Karakawa, S. Sugiura and T. Araki, Agric. Biol. Chem., 49, 877 (1985).

12) N. Kunita, Med. J. Osaka Univ., 6, 697 (1955).

13) K. Adachi, Y. Takeda, S. Senoh and H. Kita, Biochim. Biophys. Acta, 93, 483 (1964).

14) E. R. Blakley, W. Kurz, H. Halvorson and F. J. Simpson, Can. J. Microbiol., 13, 147 (1967).

15) W. Wegst and F. Lingens, Hoppe-Seyler's Z. Physiol. Chem., 362, 1219 (1981).

16) F. Yoshizako, A. Nishimura and T. Ueno, Annu. Rep. Radiat. Cent. Osaka Prefect., 20, 115 (1979).

17) V. L. Sparnins, J. J. Anderson, J. Omans and S. Dagley, J. Bacteriol., 136, 449 (1978).

18) H. Yoshii, J. Antibiot. Ser. B, 8, 387 (1955).

19) F. Yoshizako, M. Chubachi, A. Nishimura and T. Ueno, Can. J. Microbiol., 23, 1140 (1977).

20) R. A. Cooper and M. A. Skinner, J. Bacteriol., 143, 302 (1980).

21) M. Isono, Nippon Nôgeikagaku Kaishi, 30, 802 (1956). 